\title{
Shaking table test and verification of development of an accumulated semi-active hydraulic damper as an active interaction control device
}

\author{
MING-HSIANG SHIH ${ }^{1}$ and WEN-PEI SUNG ${ }^{2, *}$ \\ ${ }^{1}$ Department of Civil Engineering, National Chi-Nan University, Pu-Li, Nan-Tou 545, Taiwan \\ ${ }^{2}$ Department of Landscape Architecture, Integrated Research Center for Green Living Technologies, National \\ Chin-Yi University of Technology, Taichung 41170, Taiwan \\ e-mail: iloveaachen@gmail.com; wps@ncut.edu.tw
}

MS received 17 July 2015; accepted 19 June 2016

\begin{abstract}
Semi-active control is based on the use of the emerging concept of active control and passive control. The developed accumulator semi-active hydraulic damper (ASHD) is converted to interaction element (IE) of active interaction control (AIC). Systemic equations of motion, control law and control rulers of this proposed new AIC are studied in this research. A full-scale multiple degrees of freedom shaking table is tested to verify the energy dissipation of this proposed AIC, including test building without control, with passive control added involving various stiffness ratios and also with synchronic control added involving various stiffness ratios. Shock absorption of displacement can be up to $74-81 \%$ of that of the test structure with stiffness ratio $=2.3387$ and 1.790 at 1 st and 2nd floor under control of synchronous switch of this proposed AIC, respectively. No matter what the test structure added with various stiffeners at 1st and 2nd floor under synchronous control, test results of shock absorption ratio of acceleration show good seismic proof capability. In addition, base shear control effects of this proposed AIC method are higher than those of the test structure with various stiffeners added under passive control. These results show that AIC with stiffeners for structural control provides the characteristics of a stabilized structure under excitation of near-fault earthquake with velocity impulse action.
\end{abstract}

Keywords. Accumulator semi-active hydraulic damper (ASHD); active interaction control (AIC); stiffness ratio; full-scale shaking table test; shock absorption ratio.

\section{Introduction}

Structures of civil engineering and architecture subjected to strong ground motion often undergo enormous deformation, resulting in permanent damage to the structures or even collapse. Recently, global warming effects induced some large earthquakes around the world such as the Richter scale 9.0 event in Indonesia and Japan causing tsunami disasters and Richter scale 7.8 in Pakistan causing a new small island offshore. Also, a Richter scale 7.9 event happened in Nepal this year, causing large loss of human life and properties. These strong earthquakes bring about not only loss of many lives but also damages to many structures. Many engineers and scholars have been inspired to shelter building and civil engineering structures from this kind of earthquakes. Thus, in order to promote the seismic proof capability of structures, industry and academic society invest lots of manpower of civil engineers and material resources in studying and developing the technology of anti-seismic capability of structures.

*For correspondence
To resist invasion of seismic forces, ductility design and application of shock isolation techniques are the most often used. The main idea of ductility design is to enable inelastic deformation of structural elements to play a role of energy dissipation, thus avoiding the resonance amplification of structures. In order to ensure that structural components remain in structural stability within the range of inelastic deformation of structural elements, the detailed design of structural components must meet toughness requirements of ductility design. The advantage of this design concept is to resist earthquake forces to avoid risk of structure collapse under $P-\Delta$ effects of structural large deflection. The difference between shock isolation technology and traditional design method is that shock isolation technology applies non-traditional beams, columns, plates, walls and other structural components of added components such as vibration isolators, stiffened dampers, dampers, tuned mass blocks, tuned liquid-column damper, etc. [1-11]. According to the reports of international research, the cost of proper installing of a damping isolation system of the structure is lower than that of the traditional method of structural reinforcement. A damping isolation system mainly reduces dynamic characteristics by changing the 
structure of seismic responses of structures. Therefore, the structures in the earthquake could still be within the elastic range; a benefit of this is no huge repair costs.

There are two types of shock isolation techniques to resist invasion of seismic forces: structural isolation and structural control techniques. To study the control forces of structural control methods and their mode changes, structural control methods are divided into passive control [12-17], active control [18-22] and semi-active control [18, 23-26]. The concept of active control was proposed by Yao [27-31]. Its main idea is to provide external control forces determine by structural response of displacement and velocity. Passive control is installing a control element in the structure. In case of structural deformation, this control element develops its energy dissipation mechanism to dissipate external forces without increasing the internal energy of structure.

Semi-active control is using the emerging concept of active control and passive control; by this control method without increasing the internal energy of the structure only the control unit is used to change the control force. This control force depends on structural responses. Semi-active control combines the characteristics of the other two methods, and requires very low external energy. Therefore, in order to bring the characteristics of semi-active control into full play, a displacement semi-active hydraulic damper (DSHD) is converted to an interaction element (IE) of active interaction control (AIC) with the addition of an accumulator proposed by Shih et al [32] to replace the organization of active interaction control system proposed by Iwan [33-37]. In this paper, the developed accumulator semi-active hydraulic damper (ASHD), proposed by Shih et al [38, 39], is converted to IE. Then, in order to develop the mechanical AIC, systemic equations of motion, control law and control rulers of this proposed new AIC are studied in this research. Then, full-scale multiple degrees of freedom shaking table tests are applied to verify the energy dissipation of this proposed interaction components of active interaction control including timely play loose and locking effect. A series of tests, including test building without control, with passive control added involving various stiffness ratios and also with synchronic control added involving various stiffness ratios, are carried out to compare the shock absorption effects of this proposed AIC under different control methods.

\section{Organization of hydraulic interaction interface elements}

The main component of this proposed active interaction control device is similar to that of an accumulated semiactive hydraulic damper (ASHD) [38, 39]. Herein, the ASHD system is composed of a hydraulic jack, directional valve, accumulator, check valves, relief valves and appropriate circuits as shown in figures 1 and 2. Major

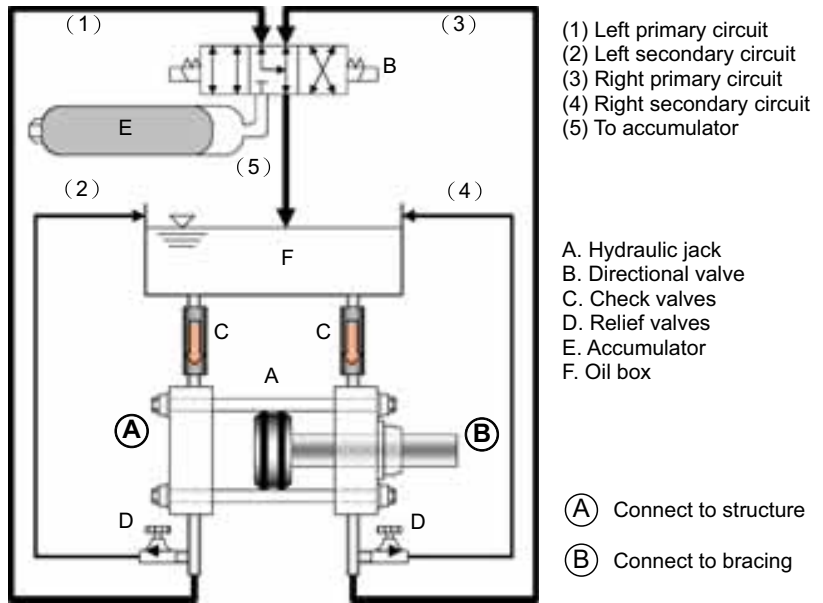

Figure 1. Construction of an ASHD [38].

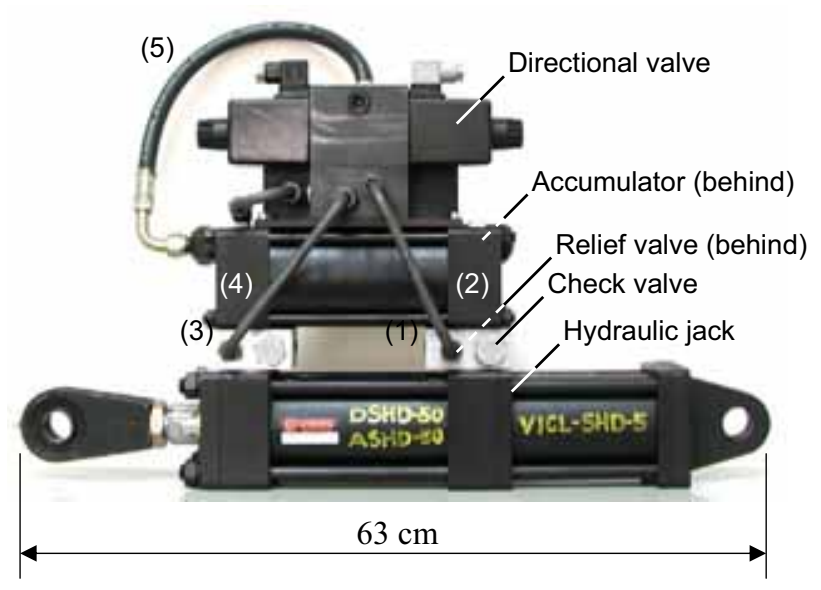

Figure 2. The prototype of ASHD [38].

components of the proposed hydraulic IE with their functions are briefly described as follows.

A. The hydraulic jack translates the control force between conjunction points of the structure to be controlled. Under the assumption of incompressibility of oil, the deformation of the jack is strictly restrained if the entire opening of the jack is closed. In the case where an appropriate flowing circuit is possible, elongation or shortening is possible without resistance.

B. The directional valve is a solenoid valve, which controls the flow direction of oil. In comparison to proportion valves and servo valves, the directional valve regulates the flow direction in switching type, generally in three states. As a result of requirements on a precise controller, the directional valve is more economical and feasible than the others.

C. Check valves are generally used to restrain the flow direction of oil pipes. Based on the functioning of a check valve, the ASHD can release the deformation of jack in one specific direction. 
D. The relief valve can also restrain the flow direction. Additionally, the relief valve limits the maximal pressure of the oil in connected pipe. If the preset maximal pressure is exceeded, flow through the valve is permissible.

E. The accumulator is generally used to minimize the fluctuation of oil pressure. The ASHD utilizes the accumulator to temporarily store the energy transferred from the mechanical energy of the structure. Additionally, the accumulator provides a high initial pressure by changing the state of directional valve.

F. The oil box contains the oil for balancing the volume loss induced by compressive deformation.

The consumable energy of this ASHD is converted to potential energy and stored in the accumulator directly. This not only reduces the temperature increase of the hydraulic oil but also switches the potential energy of accumulator to control force for the right moment. Initially, external forces cause deformation, and deformation is changed to electric energy (sensor), generating a series of operations and switching (computer) by electric energy; the electromagnetic valve is switched. Finally, the generated electric power drives the direction control valve (switch controller). These actions of semi-active control require only external power supply, but, the greatest bane of this method is time delay. Therefore, to reduce the disadvantages of this time-delay problem of semi-active hydraulic damper, Shih et al [38] proposed to apply an accumulator. Presently, this accumulator is linked directly to the head and tail of above work sequence. This semi-active control system gets rid of the dependency on external energy completely to eliminate the loss of time delay, resulting in better effect of seismic proof capability.

\section{Concept of this proposed AIC}

The active interaction control (AIC) due to Iwan [33] is a type of semi-active control technology and consists of a primary structure (PS), auxiliary structure (AS) and an interaction element (IE). A control computer is included to manage the control law implementation and control commands are issued to govern the control computer and detect status of structural response of sensors. Figure 3 shows the organizational structure of active interaction control system proposed by Iwan [33]. The concept of interaction control is to install an auxiliary structure or some auxiliary structures into the primary structure. The auxiliary structure is provided with a mass-stiffness-damping oscillator, which can stand alone or be combined for vibration by the interface between the switching of interface element (IE).

High-frequency characteristics of the AS show that this AS is under the excitation of extremely high frequency when it is in the status of unlock. Therefore, Shih [40] proposed the concept of directional connection, provided with the action of single-directional unlock. The AS system can join when

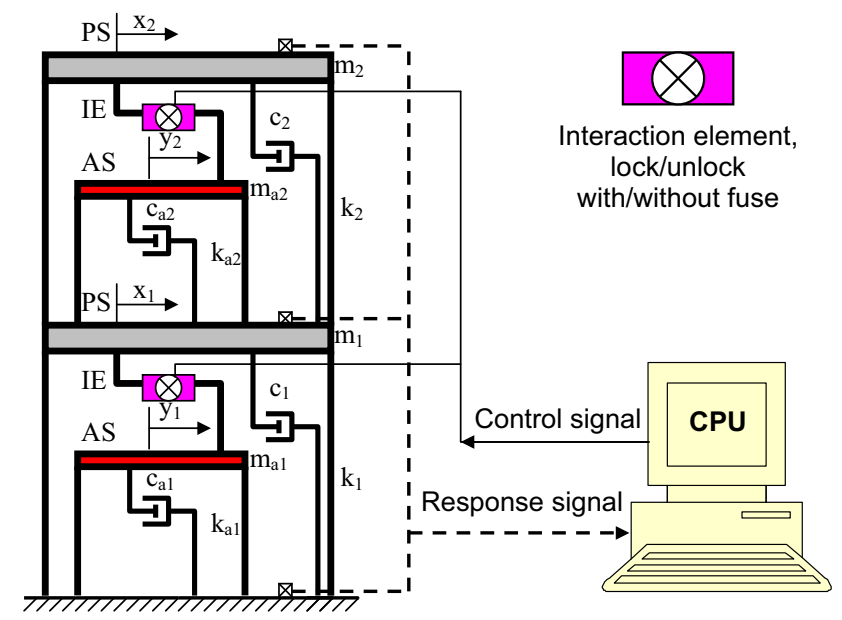

Figure 3. The structural organization of active interaction control system, proposed by Iwan [33].

relative velocity of the primary structure is reversed based on the directional connection. AS is unlocked in one direction; then, the directional join can reconnect auto-completely for the opportune moment. Therefore, the IE of organizational structure of active interaction control system is replaced by this proposed AIC device, shown in figure 4. In this study, the accumulated semi-active hydraulic damper (ASHD) is applied as an interaction element of active interaction control (AIC) to detect and join the action of relative movement autocompletely.

\section{Theoretical derivation}

\subsection{Dynamic equilibrium equation of motion of this AIC}

The organizational structure of active interaction control system, shown in figure 4, has two auxiliary structures

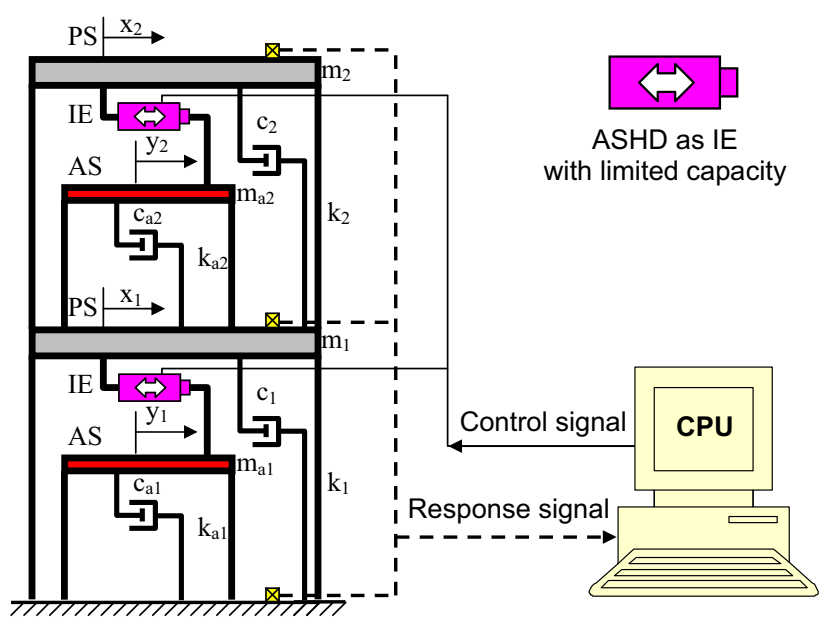

Figure 4. The frame structure of this proposed AIC system. 
installed in this primary structure with two degrees of freedom. Therefore, the dynamic equilibrium equation of motion for these four mass blocks under excitation of earthquake forces is listed as follows:

$$
\begin{aligned}
& m_{1} \ddot{x}_{1}+\left(c_{1}+c_{2}+c_{a 2}\right) \dot{x}_{1}-c_{2} \dot{x}_{2}-c_{a 2} \dot{x}_{a 2} \\
& \quad+\left(k_{1}+k_{2}+k_{a 2}\right) x_{1}-k_{2} x_{2}-k_{a 2} x_{a 2}=-m_{1} \ddot{x}_{g}+f_{I E 1}
\end{aligned}
$$

$m_{2} \ddot{x}_{2}-c_{2} \dot{x}_{1}+c_{2} \dot{x}_{2}-c_{a 2} \dot{x}_{a 2}-k_{2} x_{1}+k_{2} x_{2}=-m_{2} \ddot{x}_{g}+f_{I E 2}$

$$
\begin{gathered}
m_{a 1} \ddot{x}_{a 1}+c_{a 1} \dot{x}_{a 1}+k_{a 1} x_{1}=-m_{a 1} \ddot{x}_{g}-f_{I E 1} \\
m_{a 2} \ddot{x}_{a 2}-c_{a 2} \dot{x}_{1}+c_{a 2} \dot{x}_{a 2}-k_{a 2} x_{1}+k_{a 2} x_{a 2}=-m_{a 2} \ddot{x}_{g}-f_{I E 2}
\end{gathered}
$$

where $m, c$ and $k$ are the mass, damping ratio and stiffness, respectively, of the primary structure and auxiliary structures. The suffixes are explained in figure $4 ; x_{1}$ and $x_{2}$ represent the structural displacement of the 1 st and 2 nd floor, respectively, with reference to earth surface as the reference frame; $x_{a 1}$ and $x_{a 2}$ are sub-structural displacement of the 1 st and 2 nd floor, with reference to earth surface as the reference frame; $\ddot{x}_{g}$ is the acceleration of ground motion; $f_{I E 1}$ and $f_{I E 2}$ represent the internal force of interface element of the 1st and 2nd sub-structure, respectively. Let the tension be positive. Equations (1)-(4) are rewritten in a matrix form as follows:

$$
M \ddot{\vec{x}}+C \dot{\vec{x}}+K \vec{x}=-\vec{m}_{L} \ddot{x}_{g}+\vec{u}
$$

where $M, C$ and $K$ represent the matrix of mass, damping and stiffness, respectively; $\vec{m}_{L}$ is the distribution vector of earthquake force; $\vec{u}$ is the vector of control force.

All parameters of left hand side of Eq. (5) are constant systemic parameters. The first item of the right hand side in the equation is the uncontrollable external force; only controllable item is the second part-controllable vector of right hand side equation. This controllable vector converts part of controllability of interaction interface element via switching IE. Each status of control force vector of interaction interface element is discussed as follows.

1. Unlocked status of interaction IE: control force of IE is zero. auxiliary structures may undergo free vibration.

2. Locked status of interaction IE: there is an acting interaction force. The relative displacement of mass

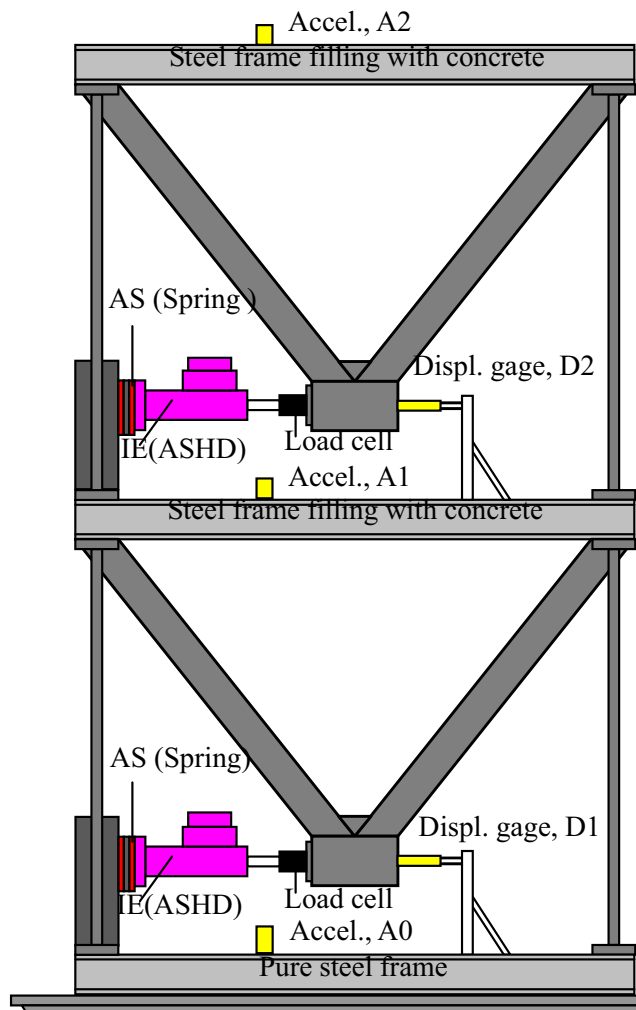

Shaking table

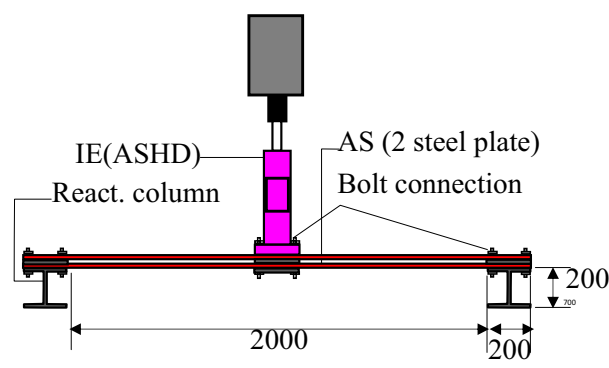

(b) Top view of spring system unit: $\mathrm{mm}$

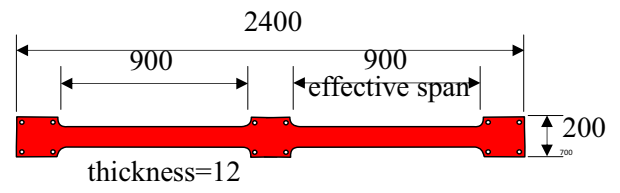

(c) Steel plate as spring element unit: $\mathrm{mm}$

(a) Front view of the structure and control components

Figure 5. The test structure added with IE (purple), AS (red) and sensors (yellow). 
between the primary structure and auxiliary structures cannot change. Therefore, the relative displacement before unlocked status is equal to that of just locked status or

$$
x_{i}(t)-x_{a i}(t)=x_{i}\left(t_{0}\right)-x_{a i}\left(t_{0}\right), t_{0} \leq t \leq t_{1}
$$

where $t_{0}$ and $t_{1}$ represent the beginning point-in-time of the locked and unlocked status, respectively. Suffix $i$ means the $i$ th element of IE. Equation (6) is suitable only for the time between $t_{0}$ and $t_{1}$. Therefore, the constraint condition is applied to represent the relations of displacement response of auxiliary structures and primary structures, as follows:

$$
x_{a i}(t)=x_{i}(t)-x_{i}\left(t_{0}\right)+x_{a i}\left(t_{0}\right)
$$

Table 1. Formula of various conditions of tuned interaction damping (TID).

\begin{tabular}{lcc}
\hline Control law & Unlocked condition of IE & Restore to locked condition of IE \\
\hline Tuned interaction damping, TID & $u_{i}(t) \dot{x}_{a i}(t)>0$ & $\dot{x}_{a, i}=\dot{x}_{i}$ \\
\hline
\end{tabular}

Table 2. The maximum structural response of test structure under excitation of El Centro earthquake record.

\begin{tabular}{lclrrrrr}
\hline $\begin{array}{l}\text { No. of stiffeners } \\
\text { at 1st floor }\end{array}$ & $\begin{array}{c}\text { No. of stiffeners } \\
\text { at 2nd floor }\end{array}$ & Control method & $\begin{array}{c}\text { D1 } \\
\mathrm{mm}\end{array}$ & $\begin{array}{c}\mathrm{D} 2 \\
\mathrm{~mm}\end{array}$ & $\begin{array}{r}\mathrm{A} 1 \\
\mathrm{gal}\end{array}$ & $\begin{array}{r}\mathrm{A} 2 \\
\mathrm{gal}\end{array}$ & $\begin{array}{c}\text { Base shear } \\
\mathrm{kN}\end{array}$ \\
\hline 0 & 0 & Without control & 25.8 & 16.8 & 105.7 & 135.3 & 8.2 \\
2 & 2 & Passive control & 17.5 & 9.9 & 139.3 & 170.1 & 12.4 \\
4 & 3 & Passive control & 14.0 & 10.7 & 161.6 & 240.8 & 15.8 \\
2 & 2 & Synchronic control & 11.0 & 7.3 & 90.3 & 126.7 & 8.1 \\
4 & 3 & Synchronic control & 6.5 & 4.1 & 88.3 & 137.9 & 9.4 \\
\hline
\end{tabular}

Table 3. The maximum structural response of test structure under excitation of Kobe earthquake record.

\begin{tabular}{lccccccc}
\hline $\begin{array}{l}\text { No. of stiffeners } \\
\text { at 1st floor }\end{array}$ & $\begin{array}{c}\text { No. of Stiffeners } \\
\text { at 2nd floor }\end{array}$ & Control method & $\begin{array}{c}\mathrm{D} 1 \\
\mathrm{~mm}\end{array}$ & $\begin{array}{c}\mathrm{D} 2 \\
\mathrm{~mm}\end{array}$ & $\begin{array}{c}\mathrm{A} 1 \\
\mathrm{gal}\end{array}$ & $\begin{array}{c}\mathrm{A} 2 \\
\mathrm{gal}\end{array}$ & $\begin{array}{c}\text { Base shear } \\
\mathrm{kN}\end{array}$ \\
\hline 0 & 0 & Without control & 28.8 & 21.7 & 163.7 & 175.1 & 9.0 \\
2 & 2 & Passive control & 24.53 & 15.84 & 236.64 & 260.67 & 19.11 \\
4 & 3 & Passive control & 16.1 & 12.8 & 186.3 & 285.4 & 18.4 \\
2 & 2 & Synchronic control & 14.7 & 9.1 & 102.6 & 159.8 & 11.3 \\
4 & 3 & Synchronic control & 5.6 & 4.4 & 71.0 & 157.7 & 5.8 \\
\hline
\end{tabular}

Table 4. The ratios of maximum shock absorption of test structure under excitation of El Centro earthquake record.

\begin{tabular}{lccccccc}
\hline $\begin{array}{l}\text { No. of stiffeners } \\
\text { at 1st floor }\end{array}$ & $\begin{array}{c}\text { No. of stiffeners } \\
\text { at 2nd floor }\end{array}$ & Control method & D1 $(\%)$ & D2 $(\%)$ & A1 (\%) & A2 (\%) & $\begin{array}{c}\text { Base } \\
\text { shear }(\%)\end{array}$ \\
\hline 0 & 0 & Without control & 0 & 0 & 0 & 0 & 0 \\
2 & 2 & Passive control & 32.17 & 41.07 & -31.79 & -25.72 & -51.22 \\
4 & 3 & Passive control & 45.74 & 36.31 & -52.89 & -79.97 & -92.68 \\
2 & 2 & Synchronic control & 57.36 & 56.55 & 14.57 & 6.36 & 1.22 \\
4 & 3 & Synchronic control & 74.81 & 75.60 & 16.64 & -1.92 & -14.63 \\
\hline
\end{tabular}

\begin{tabular}{|c|c|c|c|c|c|c|c|}
\hline $\begin{array}{l}\text { No. of stiffeners } \\
\text { at } 1 \text { st floor }\end{array}$ & $\begin{array}{l}\text { No. of stiffeners } \\
\text { at } 2 \text { nd floor }\end{array}$ & Control method & D1 (\%) & D2 (\%) & $\mathrm{A} 1(\%)$ & A2 $(\%)$ & $\begin{array}{c}\text { Base } \\
\text { shear }(\%)\end{array}$ \\
\hline 0 & 0 & Without control & 0 & 0 & 0 & 0 & 0.0 \\
\hline 2 & 2 & Passive control & 14.83 & 27.00 & -44.55 & -48.87 & -112.33 \\
\hline 4 & 3 & Passive control & 44.10 & 41.01 & -13.81 & -62.99 & -104.44 \\
\hline 2 & 2 & Synchronic control & 48.96 & 58.06 & 37.32 & 8.74 & -25.56 \\
\hline 4 & 3 & Synchronic control & 80.56 & 79.72 & 56.63 & 9.94 & 35.56 \\
\hline
\end{tabular}

Table 5. The ratios of maximum shock absorption of test structure under excitation of Kobe earthquake record. 
Thus, the interaction force of the $i$ th IE is as follows:

$$
\begin{aligned}
f_{E I, i}= & -m_{a i}\left(\ddot{x}_{i}-\ddot{x}_{i-1}\right)-c_{a i}\left(\dot{x}_{i}-\dot{x}_{i-1}\right)-k_{a i}\left(x_{i}-x_{i-1}\right. \\
& \left.-x_{i, t_{0}}+x_{a i, t_{0}}\right)
\end{aligned}
$$

The integrated control force is described by Eq. (8). According to the test structure and characteristics of interaction control elements, the following assumptions can be made: (1) mass of the auxiliary structures is neglected; (2) damping of auxiliary structures is neglected; and (3) frequency of auxiliary structures is infinite. Thus, auxiliary structures are equivalent to stiffness elements. Eq. (8) can be simplified as follows:

$$
f_{E I, i}=-k_{a i}\left(x_{i}-x_{i-1}-x_{i, t_{0}}+x_{a i, t_{0}}\right)
$$

Equation (9) is substituted into Eqs. (1) and (2); then, the equation of motion can be rewritten as follows:

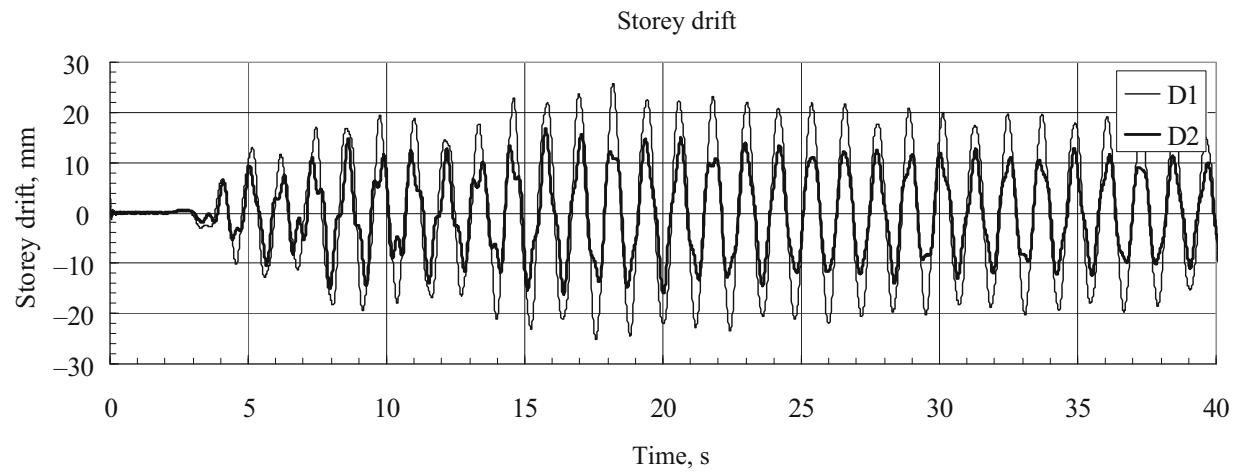

(a) Storey drift

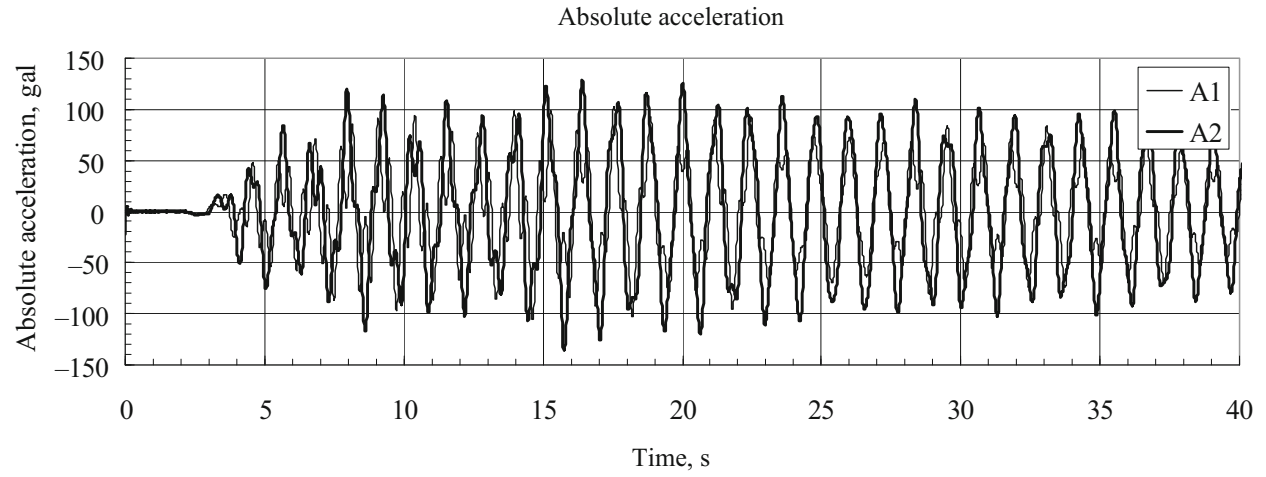

(b) Absoulte acceleration

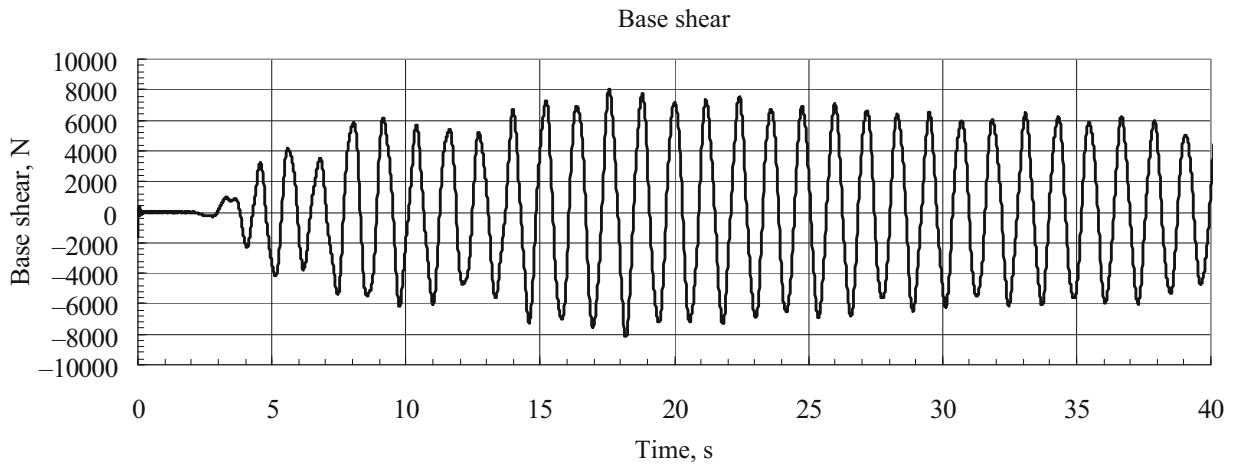

(c) Base shear

Figure 6. Time history responses of bare structure without stiffness and control under excitation of El Centro 1940 earthquake record. 


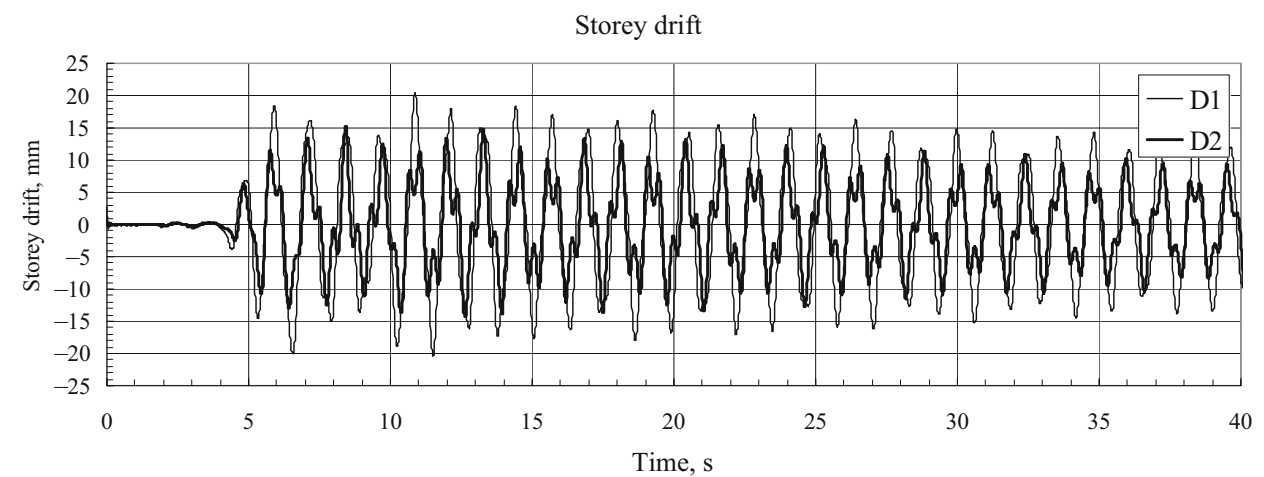

(a) Storey drift

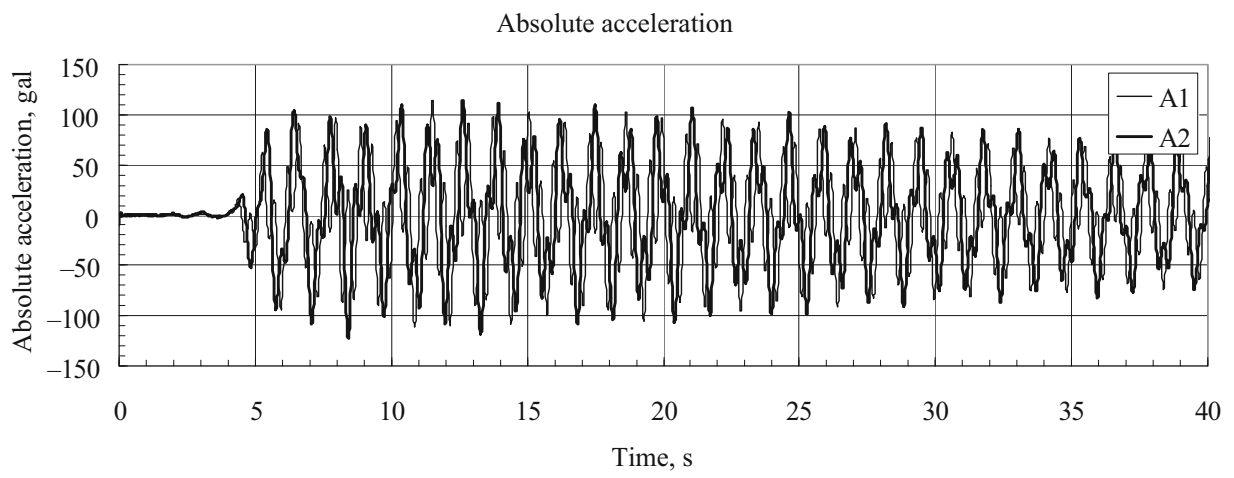

(b) Absoulte acceleration

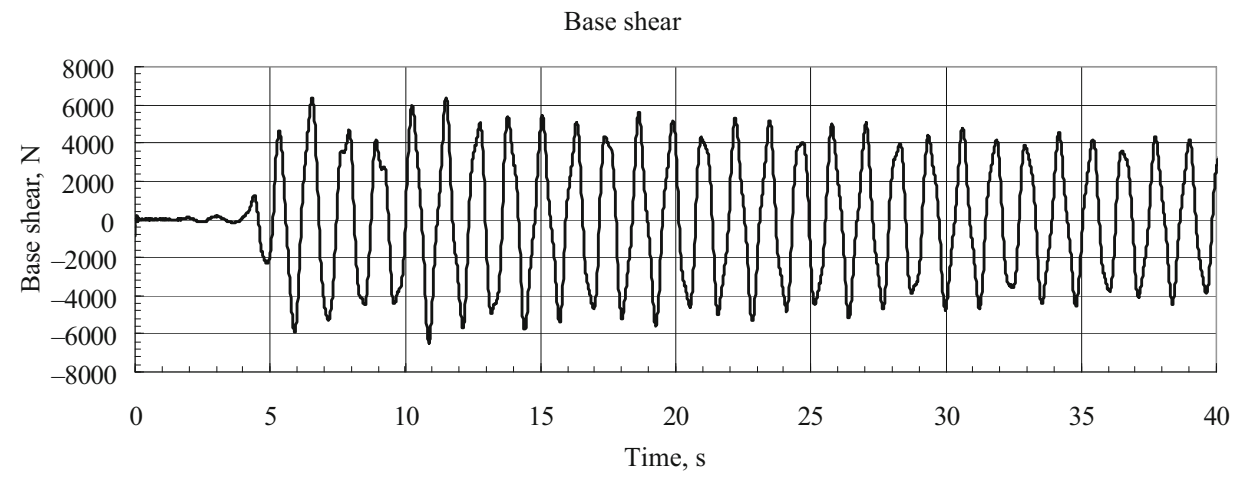

(c) Base shear

Figure 7. Time history responses of bare structure without stiffness and control under excitation of Kobe earthquake record.

$$
\begin{gathered}
m_{1} \ddot{x}_{1}+\left(c_{1}+c_{2}\right) \dot{x}_{1}-c_{2} \dot{x}_{2}+\left(k_{1}+k_{2}\right) x_{1}-k_{2} x_{2} \\
=-m_{1} \ddot{x}_{g}+f_{I E 1} \\
m_{2} \ddot{x}_{2}-c_{2} \dot{x}_{1}+c_{2} \dot{x}_{2}-k_{2} x_{1}+k_{2} x_{2}=-m_{2} \ddot{x}_{g}+f_{I E 2} \\
k_{a 1} x_{a 1}=-f_{I E 1} \\
k_{a 2}\left(x_{a 2}-x_{1}\right)=-f_{I E 2}
\end{gathered}
$$

where the interface force is shown as follows:

$$
f_{E I, i}=-k_{a i}\left(x_{i}-x_{i-1}\right)+k_{a i}\left(x_{i, t_{0}}-x_{a i, t_{0}}\right)
$$

The degrees of freedom of auxiliary structures can be neglected.

Therefore, Eq. (5) can be rewritten as follows:

$$
M \ddot{\vec{x}}+C \dot{\vec{x}}+K \vec{x}=-\vec{m}_{L} \ddot{x}_{g}+u(t)+u_{2}(t)
$$

where $M, C$ and $K$ represent the matrix of mass, damping and stiffness of primary structure, respectively. All matrixes are $n \times n ; \ddot{x}, \dot{x}$ and $x$ represent acceleration, velocity and displacement vectors of the primary structure with respect to ground fixed point; the dimension is $n . L$ is 
an $n$-dimensional unit vector. All elements of these vectors are $1.0 ; \ddot{x}_{g}$ is ground acceleration and $u(t)$ is control force, i.e., interaction interface force of IE; $u_{2}(t)$ is transmitted force to supported floor form the auxiliary structure. This study considers auxiliary structures as independent oscillators. The equation of motion of each auxiliary structure can be expressed as follows:

$$
\begin{aligned}
& m_{a, i} \ddot{x}_{a, i}(t)+c_{a, i} \dot{x}_{a, i}(t)+k_{a, i} x_{a, i}(t) \\
& \quad=-m_{a, i} \ddot{x}_{g}(t)+c_{a, i} \dot{x}_{i-1}(t)+k_{a, i} x_{i-1}(t)-u_{i}(t)
\end{aligned}
$$

where suffix $a, i$ represents systemic parameter of the $i$ th floor of auxiliary structure; $u_{i}(t)$ is the $i$ th element force of IE.

\subsection{Vector of control force}

Internal force of interaction IE is relative to the status of element. These internal forces can be defined as follows.

1. Locked status of interaction IE:

$$
\begin{aligned}
u_{i}(t)= & -\left(m_{a, i}\left(\ddot{x}_{a, i}(t)+\ddot{x}_{g}(t)\right)+k_{a, i}\left(x_{a, i}(t)-x_{i-1}(t)\right)\right. \\
& \left.+c_{a, i}\left(\dot{x}_{a, i}(t)-\dot{x}_{i-1}(t)\right)\right) .
\end{aligned}
$$

2. Unlocked status of interaction IE:

$$
u_{i}(t)=0
$$

Storey drift

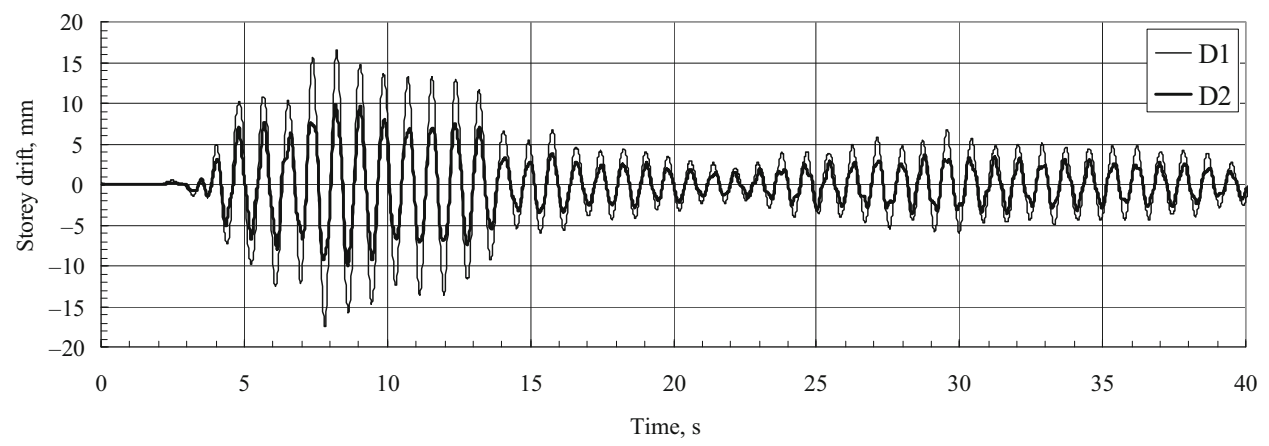

Absolute acceleration

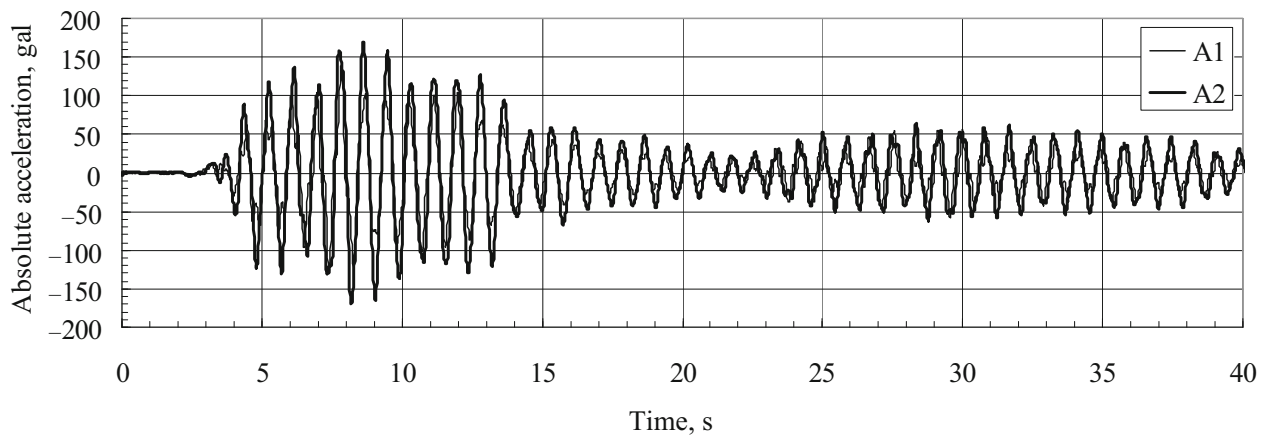

Base shear

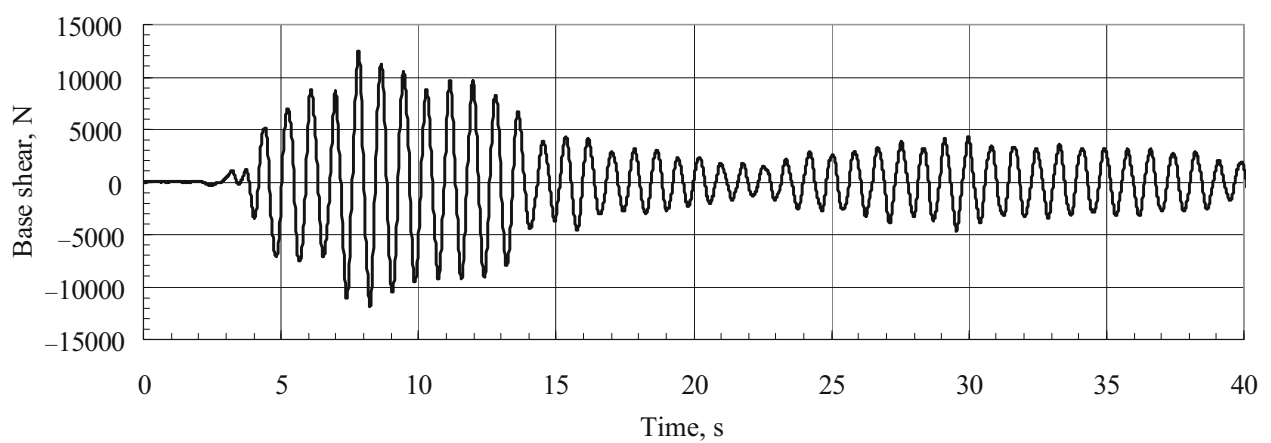

Figure 8. Time history response of test building under passive control and stiffness ratio $=1.193$ under excitation of El Centro 1940 earthquake record. 


\subsection{Control law}

The objective of control law derivation is to obtain the minimum mechanical energy of the primary structure. Thus, the mechanical energy of primary structure can be defined as the performance index

$$
J(t)=\frac{1}{2} \dot{x}^{T}(t) M \dot{x}(t)+\frac{1}{2} x^{T}(t) K x(t)
$$

Variance ratio of mechanical energy of the primary structure can be obtained from Eq. (15) based on the Hamilton principle [41, 42] by moving the damping item from the left hand side to the right hand side. Then, Eq. (20) is the inner product of Eq. (19) and velocity vector of the structure is

$$
\dot{J}(t)=\left(-C \dot{x}(t)-\vec{m}_{L} \ddot{x}_{g}(t)+u(t)+u_{2}(t)\right) \dot{x}(t)
$$

The only item of power that can be affected by the IE is the third item of Eq. (20). In order to achieve the minimum performance index of structure in a period at control frequency, the control force should satisfy the instant optimal control force of Eq. (21).

$$
\min :\left(u^{t}(t) \dot{x}(t)\right)
$$

\subsection{Control rules}

Equation (21) tallies with the discriminate of instant optimal control for control signal. The constraint function of
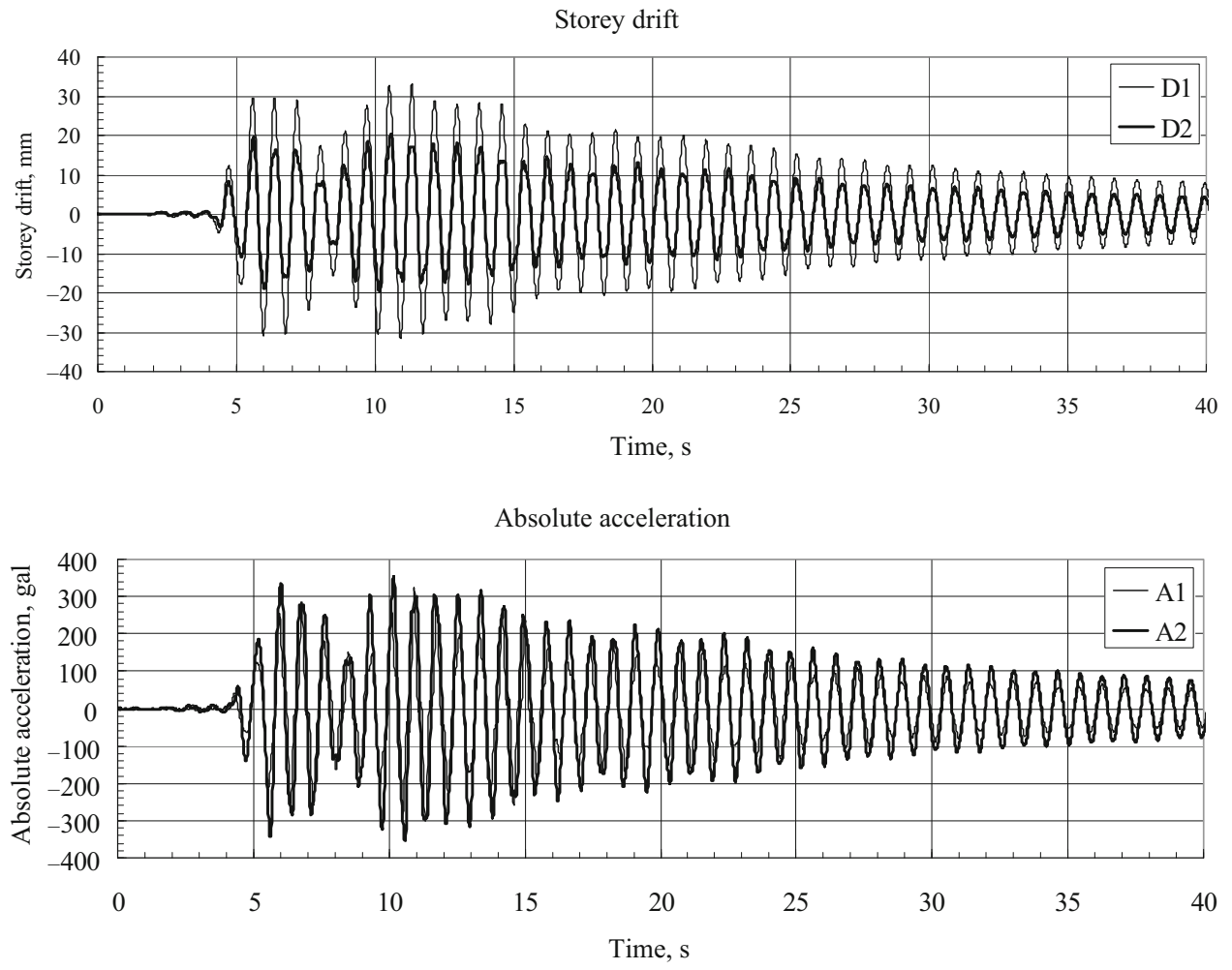

Base shear

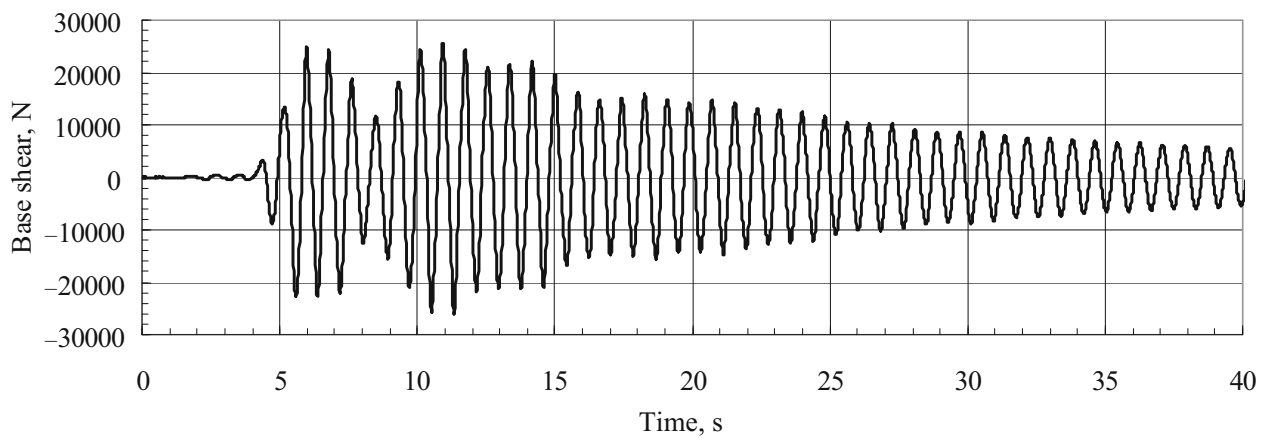

Figure 9. Time history response of test building under passive control and stiffness ratio $=1.193$ under excitation of El Centro 1940 under excitation of Kobe earthquake record. 
force of IE with a fuse should be applied to protect the elements of control force under stress. Therefore, the control law of tuned interaction damping (TID; Zhang and Iwan [34-36, 41] is a better control method, where $\dot{x}_{a i}$ is relative velocity of the storey. Table 1 lists the various control conditions of TID.

\section{Test set-up for full-scale shaking table test}

The purpose of this section is to apply a full-scale shaking table test with multiple degrees of freedom to test and verify the seismic proof capability of this proposed interaction element by active interaction structural control method. We also want to check whether this proposed IE can bring the effect of unlocking and locking into full play at the right moment or not.

\subsection{Set-up of shaking table}

The main structure consists of two steel frames filled with concrete, a pure steel frame and eight flat-rolled steel columns. Dimension of these three steel frames are $260 \times 260 \times 20 \mathrm{~cm}$ and the cross-section of flat-rolled steel is $10 \times 3.2 \mathrm{~cm}$, which is made of medium-carbon steel. Mass of steel frame filling with concrete is about $3800 \mathrm{~kg}$ and used to simulate the floor of this test frame. In

Storey drift

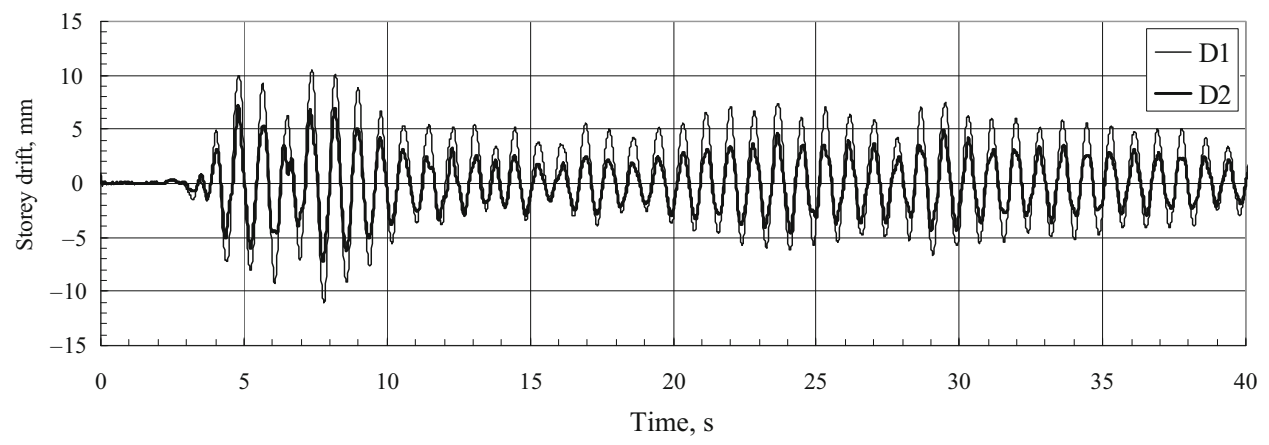

Absolute acceleration

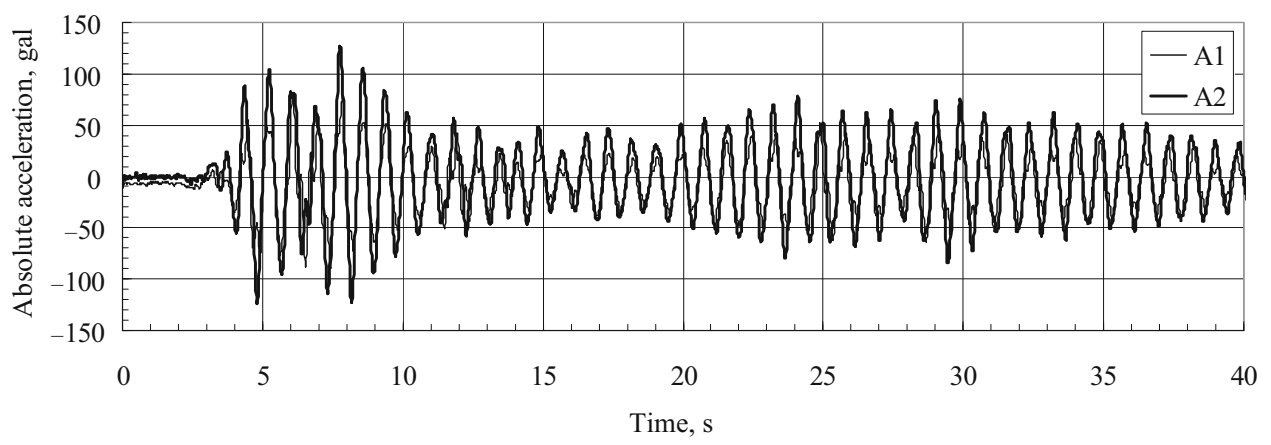

Base shear

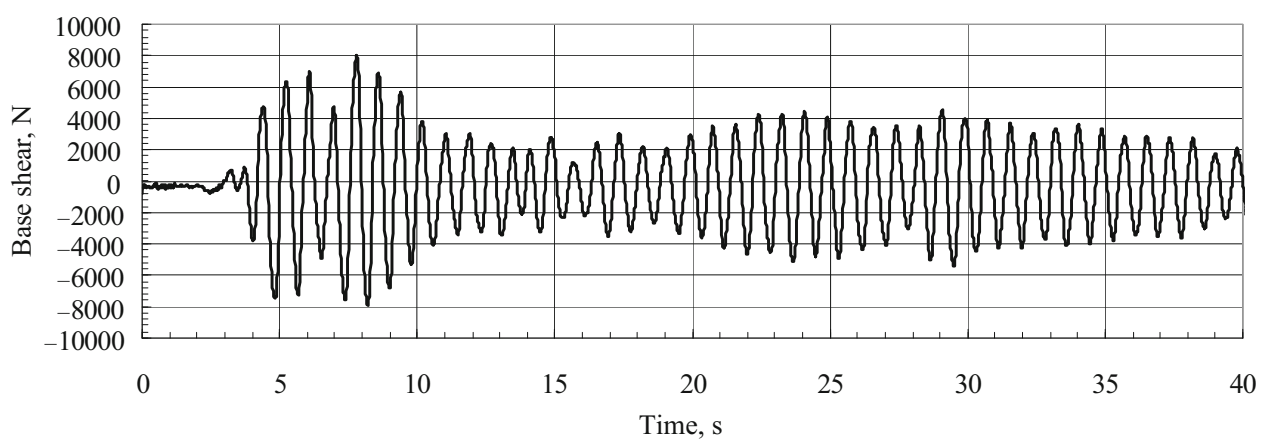

Figure 10. Time history response of test building with synchronic control and stiffness ratio $=1.193$ at each floor under excitation of El Centro 1940 earthquake record 
this shaking table, three accelerometers, two displacement gauges and two load cells are installed in this test mode to measure the absolute acceleration, storey drift and output force of damper, respectively. Figure 5 shows the test structure with added interaction element (IE), sensors such as accelerometers, displacement gauge and load cell with the auxiliary structures (AS). All structural responses of this test structure are recorded by the signal process of control computer.

\subsection{Consideration of stiffeners}

Generally, stiffness of the practical stiffening component, normally regarded as rigid, is only 5-10 times lateral stiffness. Therefore, to faithfully simulate the practical application and deformation state of stiffening, a stiffened sheet is designed to connect with IE and AS, shown in figure $5 \mathrm{~b}$ and $\mathrm{C}$. Figure $5 \mathrm{~b}$ and $\mathrm{c}$ shows a top view and side view of this designed sheet stiffener, respectively. The designed stiffener is tested by a static test. Then, all tests of this study are executed by the shaking table test, shown in figure 5 .

\section{Test results and discussion}

\subsection{Test results}

The test structure is tested without control and with passive control and 2 stiffeners (stiffness ratio $=1.193$ ) at 1 st and

Storey drift

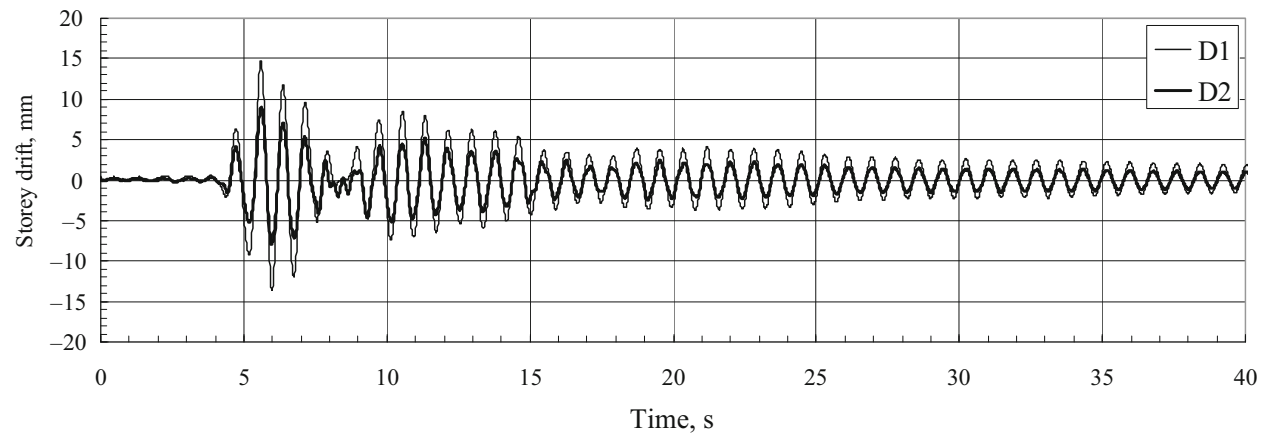

Absolute acceleration

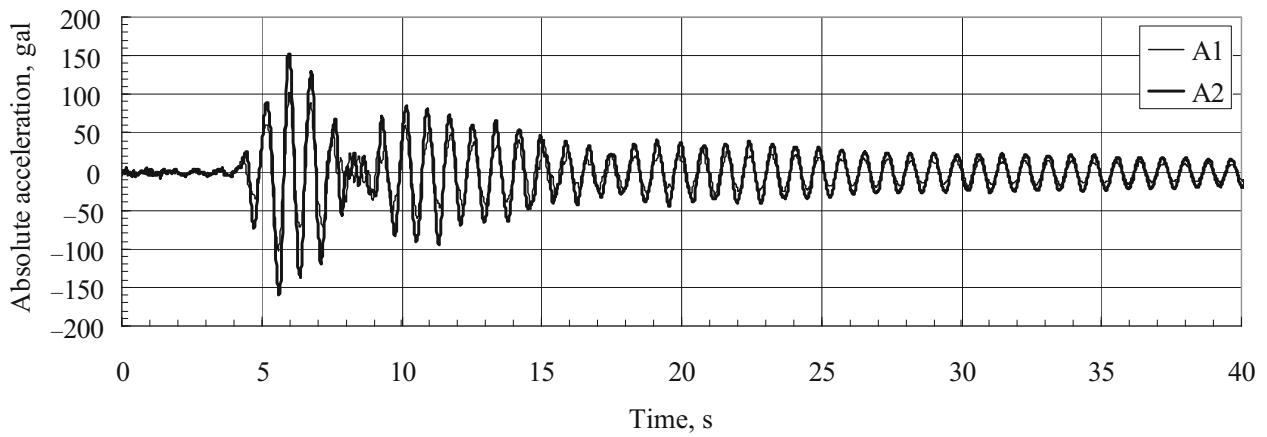

Base shear

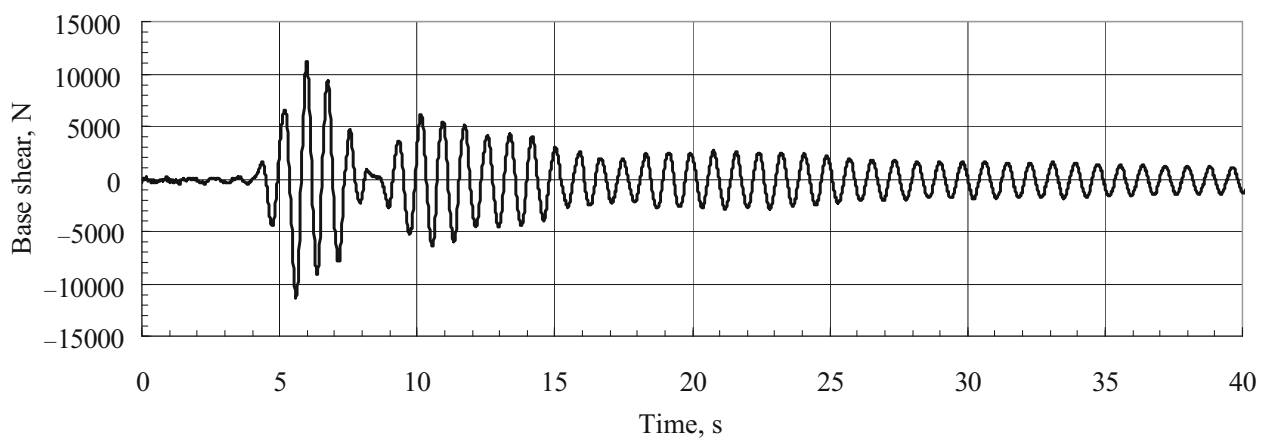

Figure 11. Time history response of test building with synchronic control and stiffness ratio $=1.193$. 

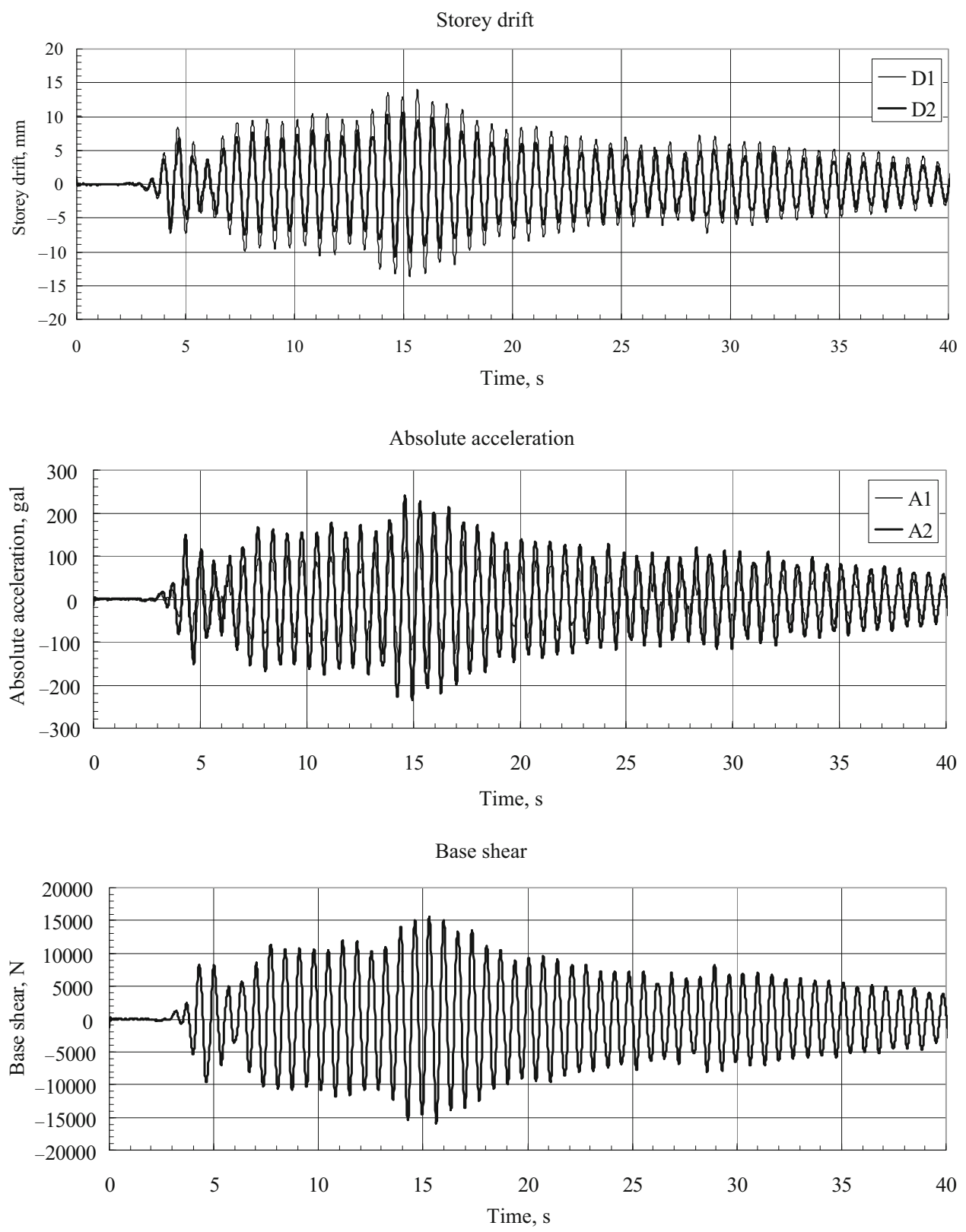

Figure 12. Time history response of test building under passive control and stiffness ratio $=2.387$ at 1 st floor and stiffness ratio $=1.790$ at 2 nd floor under excitation of El Centro 1940 earthquake record.

2nd floor, 4 stiffeners (stiffness ratio $=2.387$ ) at 1 st floor and 3 stiffeners (stiffness ratio $=1.790$ ) at 2 nd floor. Then, the test structure is studied with 2 stiffeners at 1 st and 2 nd floor, 4 stiffeners at 1 st floor and 3 stiffeners at 2nd floor with synchronic control. All test structures with various stiffeners added and various control conditions are under excitation of El Centro and Kobe earthquake record. All test results are arranged; the maximum response and ratios of the maximum shock absorption are analysed and listed in tables $2-5$. The typical time history of storey drift, absolute acceleration and base shear response of bare test structure under excitation of El Centro 1940 and Kobe earthquake are shown in figures 6 and 7. The time history of storey drift, absolute acceleration and base shear response of test structure with two stiffeners added at each floor and passive control under excitation of El Centro 1940 and Kobe earthquake is shown in figures 8 and 9, respectively; also test results of this kind of test structure with synchronic control under excitation of EL Centro 1940 and Kobe earthquake are shown in figures 10 and 11, respectively. The time history of storey drift, absolute acceleration and base shear response of test structure with 4 stiffeners added at 1 st floor, 3 stiffeners at 2 nd floor and passive control under excitation of El Centro 1940 and Kobe earthquake is shown in figures 12 and 13, respectively; also test results of this kind of test structure with synchronic control under 

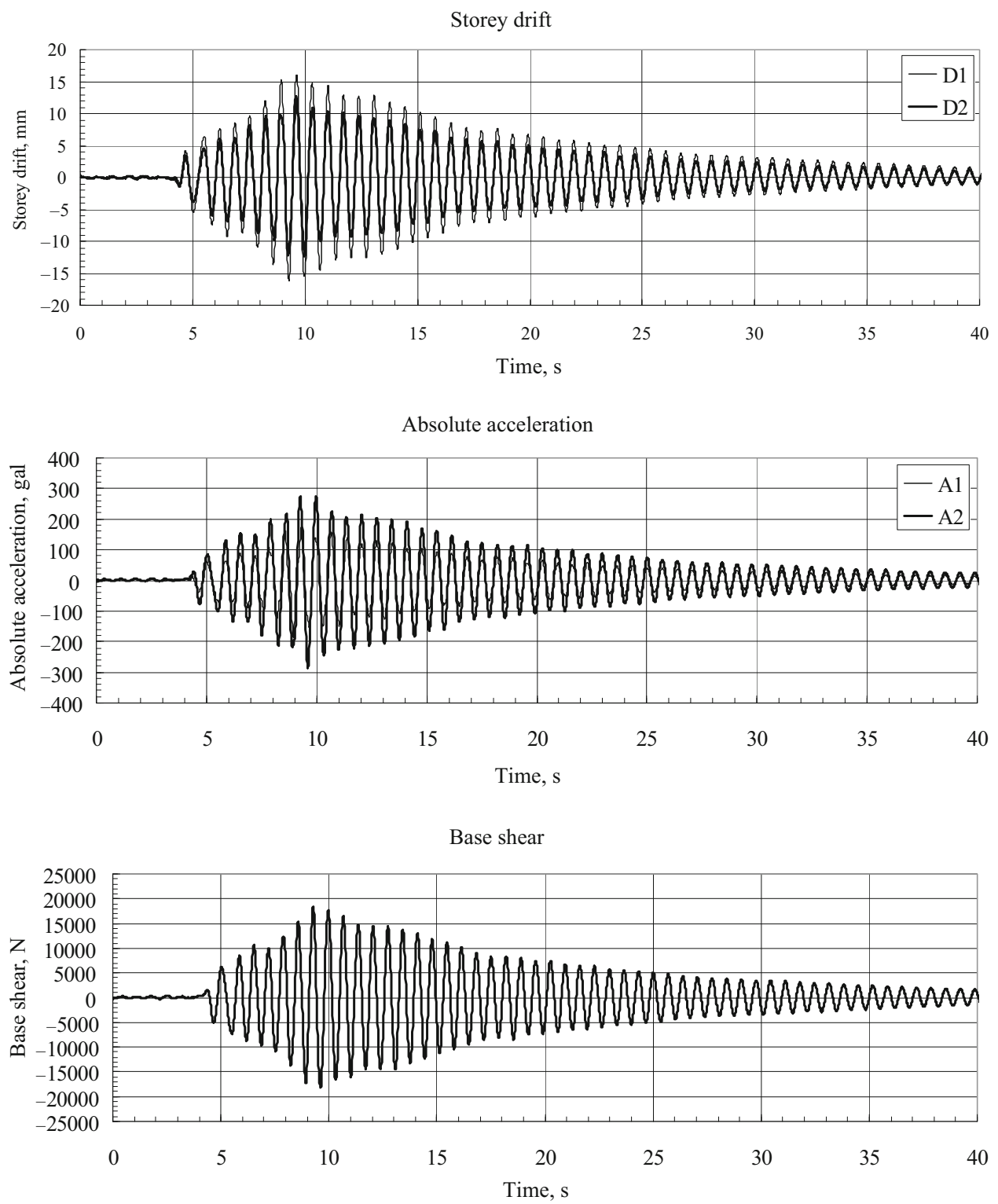

Figure 13. Time history response of test building under passive control, stiffness ratio $=2.387$ at 1 st floor and stiffness ratio $=1.790$ at 2 nd floor under excitation of Kobe earthquake record.

excitation of EL Centro 1940 and Kobe earthquake are shown in figures 14 and 15, respectively; the maximum response of base shear, acceleration records at the base, 1st floor and 2nd floor and displacement records at 1st and 2nd floor are listed in tables 2 and 3, respectively; ratios of the maximum shock absorption are listed in tables 4 and 5 , respectively.

\subsection{Discussion}

6.2a The maximum displacement and acceleration absorption effects of structure with various stiffeners under excitation of El Centro and Kobe earthquake record: All test results of these shaking tables tests display that this proposed AIC can bring effects of shock absorption of displacement and acceleration control into full play. No matter what the test structure with 2 stiffeners added at each floor or 4 stiffeners at 1 st floor and 3 stiffeners at 2nd floor with synchronic control, the displacement shock absorption ratios of these test structures under excitation of El Centro and Kobe earthquake records are almost the same. In addition, the acceleration shock absorption ratios of these test structures under excitation of Kobe earthquake records are higher than those of test structure under excitation of El Centro earthquake record. However, the control effects of acceleration and base shear of test structure with 2 stiffeners added at 1 st and 2nd floor and also 4 stiffeners and 3 stiffeners at 1st and 2nd floor with passive control are enlarged. Although structural response of displacement can be reduced by the passive stiffened structure, decrement 

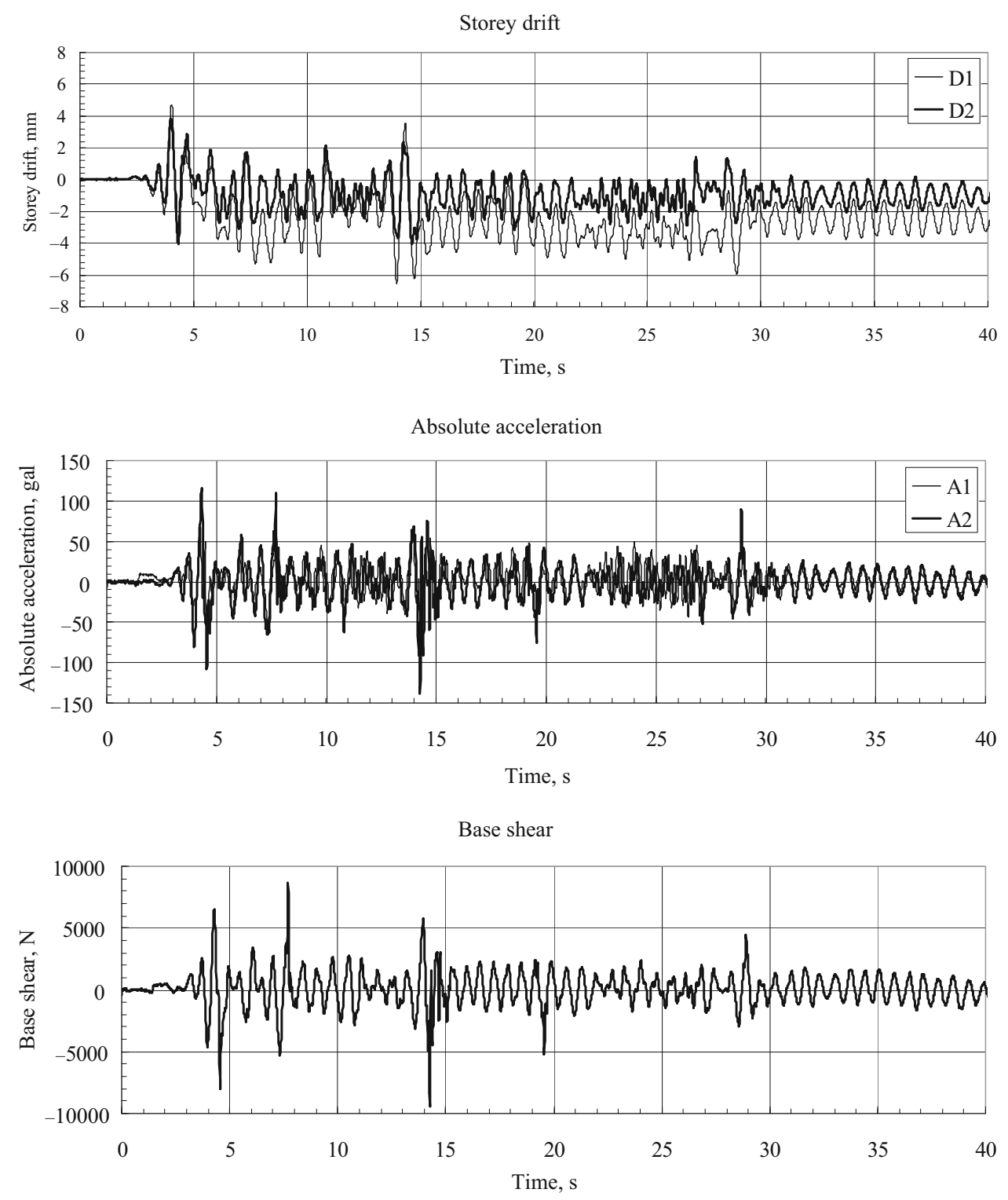

Figure 14. Time history response of test building with synchronic control, stiffness ratio $=2.387$ at 1 st floor and stiffness ratio $=1.790$ at 2 nd floor under excitation of El Centro 1940 earthquake record.

rate is not proportional to stiffness ratio. Nevertheless, the structural response of displacement and acceleration can be reduced by synchronic control of this proposed AIC; decrement rate is proportional to stiffness ratio. Actually, dynamic responses are related to structural frequencies. Even though static deformation of structure can be reduced by a stiffened structure, reduction of dynamic response is not obvious. By contrast, shock absorption of displacement is up to $50 \%$ in this proposed control system. There is strong dependency between shock absorption ratio of displacement and control parameters, for example, the shock absorption of displacement can be up to $74-81 \%$ of that of the test structure with 4 stiffeners added and 3 stiffeners at 1st and 2nd floor under the control of synchronous switch of this proposed AIC. 6.2b Influence of various steel stiffness values for auxiliary structure on control effect of this proposed AIC: The control forces of interaction system are induced earlier to the primary structure when stiffness of auxiliary structure is bigger to reduce the time-delay problem. However, when the stiffness is bigger, more impact force, amplified acceleration response and larger base shear force of structure are induced. In order to investigate the influence of stiffness of auxiliary structure on the control effect, there are two sets of the test structure of shaking table test under synchronous control to test and verify the control effects: (1) with two steel stiffeners added at 1 st and 2 nd floor (stiffness ratio is 1.193) and (2) with four steel stiffeners added at 1st floor (stiffness ratio is 2.396) and three steel stiffeners at 2 nd floor (stiffness ratio is 1.790). The 

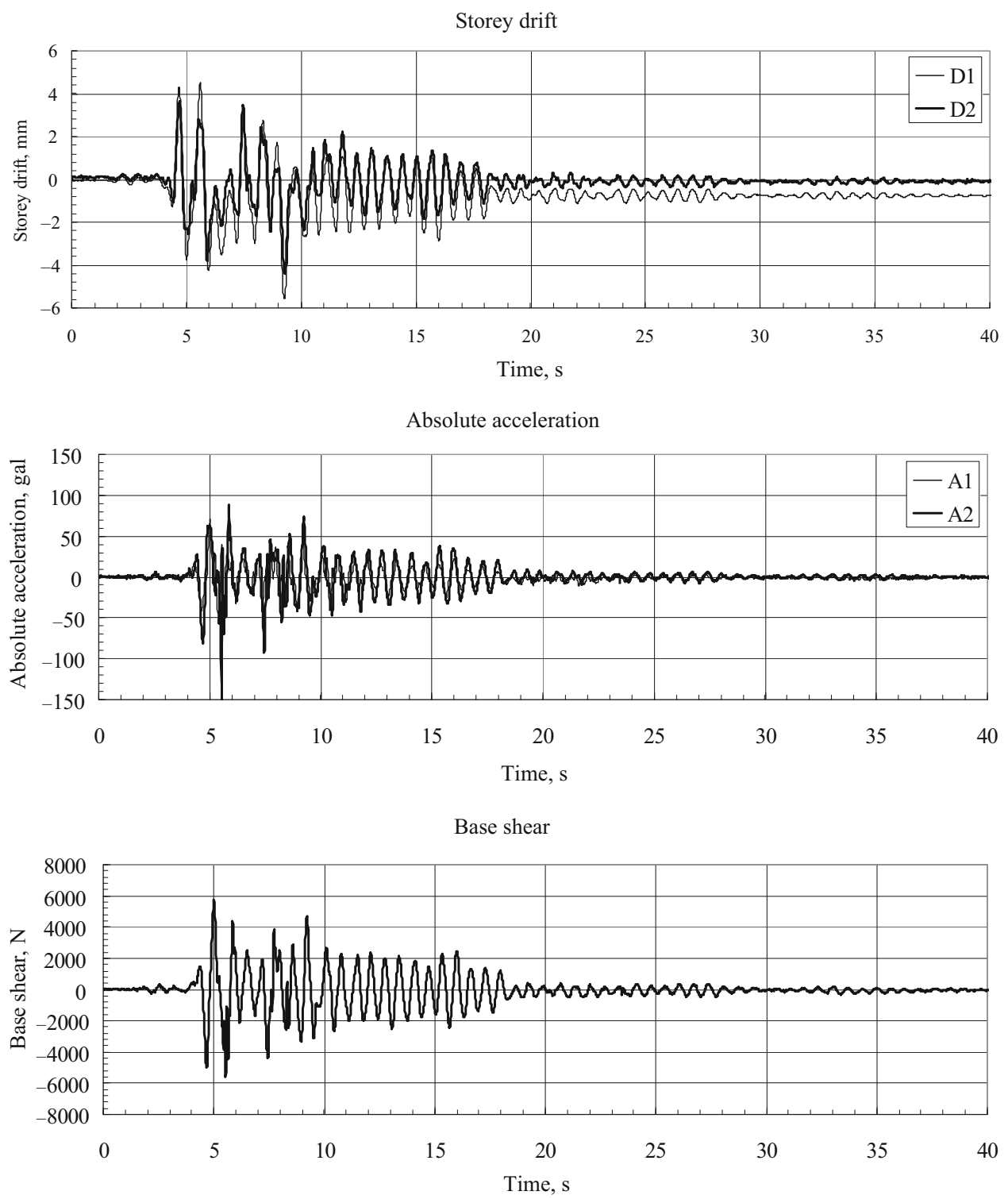

Figure 15. Time history response of test building with synchronic control, stiffness ratio $=2.387$ at 1 st floor and stiffness ratio $=1.790$ at 2 nd floor under excitation of Kobe earthquake record.

comparisons of the shock absorption ratio of test structure under excitation of various earthquake records are shown in figures 16 and 17. Figures 16 and 17 show that more stiffeners added on the auxiliary structure raise the displacement control effects for the test structure with various stiffeners added under passive control and synchronous control. Nevertheless, they cause less control effects of acceleration control for the test structure under passive control. However, test results of figures 16 and 17 reveal that the more the stiffeners for test structure under synchronous control, the more the control effects of displacements and accelerations. Regarding the difference of shock absorption ratio of displacement between the cases where stiffness ratio $=1.193$ of the test structure at each floor and stiffness ratio $=2.396$ at 1 st floor and stiffness ratio $=1.193$ at 2 nd floor of the test structure with passive control and synchronous control, the lesser one is about $15.48 \%$ and the largest one is about $38.71 \%$. Also, for the shock absorption ratio of acceleration between the cases where stiffness ratio $=1.193$ of the test structure at each floor and stiffness ratio $=2.396$ at 1 st floor and stiffness ratio $=1.193$ at 2 nd floor of the test structure with passive control, it has been enhanced. Nevertheless, no matter what the test structure with various stiffeners added at 1 st and 2nd floor under synchronous control, the test results of shock absorption ratio of acceleration are good.In addition, base shear control effects of this proposed AIC method are higher than those of the test structure added with various stiffeners under passive control. These results show that this kind of stiffened structure provides the characteristics of a stabilized structure under excitation of near-fault earthquake with velocity impulse action. 

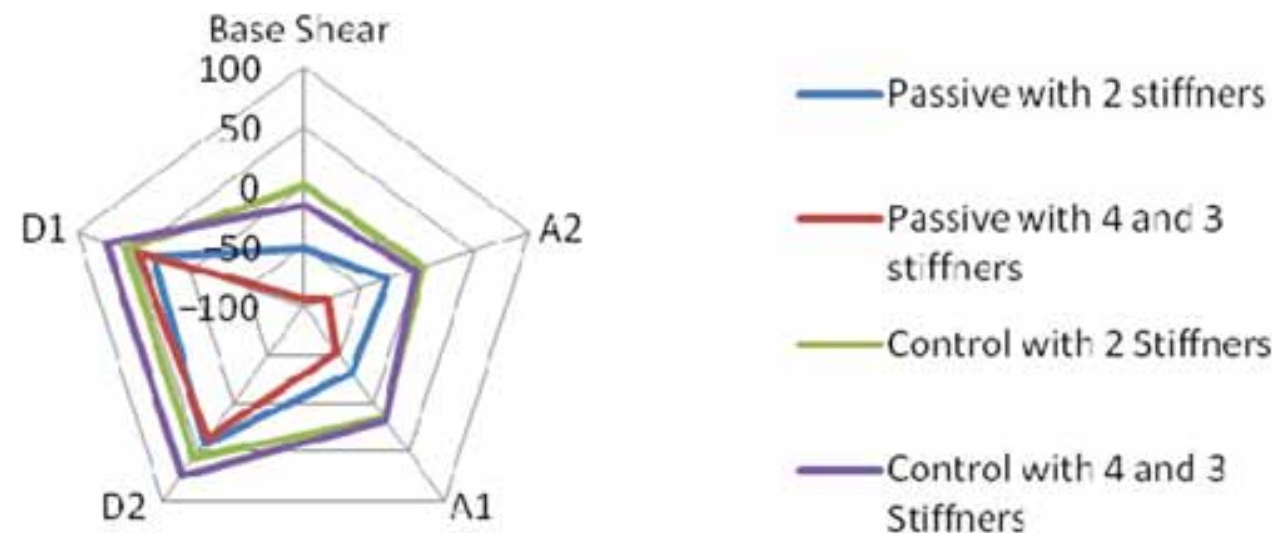

Figure 16. Comparison of shock absorption ratio of test building under excitation of El Centro Earthquake record with various control methods and with various stiffeners added.
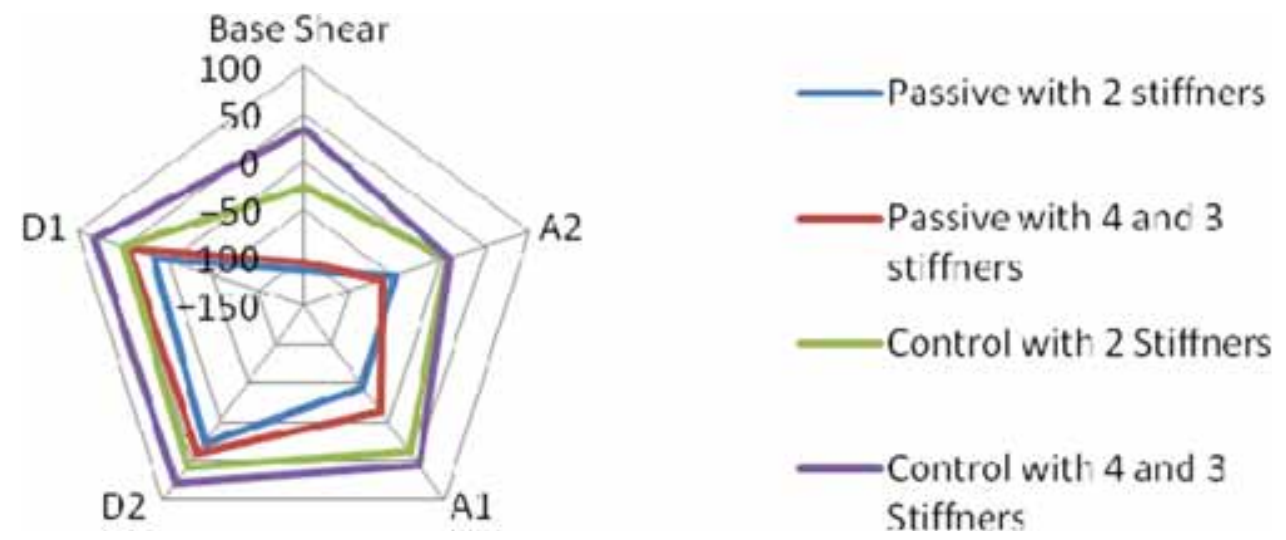

Figure 17. Comparison of shock absorption ratio of test building under excitation of Kobe Earthquake record with various control methods and with various stiffeners added.

\section{Conclusions}

ASHD was proposed by Shih et al [38, 39] to improve the time-delay problem of a semi-active hydraulic damper. In order to develop a new mechanical active interaction controller, this research converted this developed accumulator semi-active hydraulic damper (ASHD) to an interaction element of AIC. Systemic equations of motion, control law and control rulers of this proposed new AIC are studied in this research. Then, a full-scale shaking table of two storey test structure is tested for the bare structure, with various stiffeners added at different floors and passive control and synchronic control under excitation of different earthquake records. Test results of these shaking tables tests show that the test structure with various stiffeners added under synchronic control of this proposed AIC can bring about effects of shock absorption of displacement and acceleration control into full play. The following conclusions are obtained as a result of a series of experimental studies.

1. No matter what the test structure with various stiffeners added at each floor with synchronic control, the displacement and acceleration shock absorption ratios of these test structures under excitation of various earthquake records show good seismic proof capability. However, the control effects of acceleration and base shear of the test structure with various stiffeners added at each floor and passive control have been enlarged; this passive control just reduces the displacement response of test structure under external excitation.

2. Test results show that more stiffeners added on the auxiliary structure raise the displacement control effects for the test structure with various stiffeners added under passive control and synchronous control.

3. Nevertheless, they cause less control effects of acceleration control for the test structure under passive control.

4. Test results also reveal that base shear control effects of this proposed AIC method are higher than those of the test structure with various stiffeners added under passive control.

All of these results of shaking table test under various control conditions show that this kind of stiffened structure under synchronous control provides with the characteristics 
of a stabilized structure under excitation of near-fault earthquake with velocity impulse action. Also, these test results demonstrate that this developed ASHD, converted to an IE, provides high practicability for seismic proof capability of a building under external excitation.

\section{Acknowledgements}

The authors would like to acknowledge the support of Taiwan Ministry of Science and Technology through Grant Nos. MOST-103-2625-M-260-001 and MOST-103-2625M-167-001.

\section{References}

[1] Chen Z, Dian G and Huang Y 2013 Review on web buckling and hysteretic behavior of shear panel dampers. Adv. Steel Constr. 9(3): 205-217

[2] Christopoulos C and Montgomery M 2013 Viscoelastic coupling dampers (VCDs) for enhanced wind and seismic performance of high-rise buildings. Earthq. Eng. Struct. Dyn. 42(15): 2217-2233

[3] Chang M L, Lin C C, Ueng J M, Jsieh K H and Wang J F 2010 Experimental study on adjustable tuned mass damper to reduce floor vibration due to machinery. Struct. Control Health Monitor. 17(5): 532-548

[4] Das S, Gur S, Mishra S K and Chakraborty S 2015 Optimal performance of base isolated building considering limitation on excessive isolator displacement. Struct. Infrastruct. Eng. 11(7): 904-917

[5] Di Sarno L, Chioccarelli E and Cosenza E 2011 Seismic response analysis of an irregular base isolated building. Bull. Earthq. Eng. 9(5): 1673-1702

[6] Deng K, Pan P, Li W and Xue Y 2015 Development of a buckling restrained shear panel damper. J. Constr. Steel Res. 106: 311-321

[7] Li J, Chen J Y and Chen X B 2013 The analysis and application on the typhoon-induced vibration control of the wind turbine with a pendulum damper. Adv. Mater. Res. 773:193-198

[8] Nishimura A, Yamamoto H, Kimura Y, Kimura H, Yamamoto $\mathrm{M}$ and Kushibe A 2011 Base-isolated super high-rise RC building composed of three connected towers with vibration control systems. Struct. Concrete 12(2): 94-108

[9] Siringoringo D M and Fujino Y 2015 Seismic response analyses of an asymmetric base-isolated building during the 2011 Great East Japan (Tohoku) Earthquake. Struct. Control Health Monitor. 22(1): 71-90

[10] Wei L S, Zhou F L, Tan P and Ren M 2011 Research and application on three-dimensional seismic and vibration isolation for building. J. Harbin Inst. Technol. (New Series) 18 (1): 62-66

[11] Xiang P and Nishitani A 2014 Seismic vibration control of building structures with multiple tuned mass damper floors integrated. Earthq. Eng. Struct. Dyn.. 43(6): 909-925

[12] Choi K M, Jung H J, Lee H J and Cho S W 2008 Seismic protection of base-isolated building with nonlinear isolation system using smart passive control strategy. Struct. Control Health Monitor. 15(5): 785-796

[13] Chen Y, Cao T, Ma L and Luo C 2010 Structural vibration passive control and economic analysis of a high-rise building in Beijing. Earthq. Eng. Eng. Vibr. 8(4): 561-568

[14] Jung H J, Jang D D, Lee H J, Lee I W and Cho S W 2010 Feasibility test of adaptive passive control system using $\mathrm{mr}$ fluid damper with electromagnetic Induction Part. J. Eng. Mech. 136(2): 254-259

[15] Murase M, Tsuji M and Takewaki I 2013 Smart passive control of buildings with higher redundancy and robustness using base-isolation and inter-connection. Earthq. Struct. 4(6): 649-670

[16] Palacios-Quiñonero F, Rubió-Massegú J, Rossell J M and Karimi H R 2012 Semi-active-passive structural vibration control strategy for adjacent structures under seismic excitation. J. Franklin Inst. 349(10): 3003-3026

[17] Zhang Z and Balendra T 2013 Passive control of bilinear hysteretic structures by tuned mass damper for narrow band seismic motions. Eng. Struct. 54: 103-111

[18] Fisco N R and Adeli H 2011 Smart structures: Part I - Active and semi-active control. Scientia Iranica 18(3A): 275-284

[19] Liu K, Chen L X and Cai G P, 2011 Active control of a nonlinear and hysteretic building structure with time delay. Struct. Eng. Mech. 40(3): 431-451

[20] Liu K, Chen L X and Cai G P 2013 Active control of buildings with bilinear hysteresis and time delay. Int. J. Struct. Stability Dyn. 13(5): doi: 10.1142/ S0219455413500272

[21] Reza Bagerzadeh Karimi M and Mahdi Bagerzadeh Karimi M 2011 Vibration control of MDOF structure under earthquake excitation using passive control and active control. World Acad. Sci., Eng. Technol. 80: 320-325

[22] Yanik A, Aldemir U and Bakioglu M 2014 A new active control performance index for vibration control of three-dimensional structures. Eng. Struct. 62-63: 53-64

[23] Hiramoto K, Matsuoka T and Sunakoda K 2014 Simultaneous optimal design of the structural model for the semi-active control design and the model-based semi-active control. Struct. Control Health Monitor. 21(4): 522-541

[24] Pourzeynali S and Jooei P 2013 Semi-active control of building structures using variable stiffness device and fuzzy logic. Int. J. Eng. Trans. A: Basics 26(10): 1169-1182

[25] Shih M H and Sung W P 2010 A design concept of autonomous controller for improving seismic proof capability of semi-active control device. Exp. Tech. 34(4): 20-26

[26] Xu J Y, Tang J and Li Q S 2005 Semi-active control devices in structural control implementation. Struct. Des. Tall Special Build. 14(2): 165-174

[27] Basharkhah M A and Yao J T P 1982 Application of modern control theory for building structures. Purdue University, School of Civil Engineering, Structural Engineering (Technical Report) CE-STR, No. 82-29

[28] Basharkhah M A and Yao J T P 1984 Reliability aspects of structural control. Civil Eng. Syst. 1(4): 224-229

[29] Yao J P T 1972 Concept of structural control. J. Struc. Div. ASCE 98: 1567-1574

[30] Yao J T P and Natke H G 1992 Reliability of structures with active control. 92 IEEE International Conference on Fuzzy Systems : 1227-1234 
[31] Yao J T P and Natke H G 1992 Effect of active control to structural reliability. In: Proceedings of the Specialty Conference on Probabilistic Mechanics and Structural and Geotechnical Reliability, pp 373-376

[32] Shih M H and Sung W P 2014 Development of semi-active hydraulic damper as active interaction control device to withstand external excitation. Sadhana - Acad. Proc. Eng. Sci. 39(1): 123-128

[33] Hayen J C and Iwan W D 1994 Response control of structural system using active interface damping. In: Proceedings of the first World Conference on Structural Control, vol. 1, LA, California, USA, 1994

[34] Zhang Y and Iwan W D 2002 Active interaction control of civil structures. Part 1: SDOF systems. Earthq. Eng. Struct. Dyn. 31(1): 161-178

[35] Zhang Y and Iwan W D 2002 Active interaction control of civil structures. Part 2: MDOF systems. Earthq. Eng. Struct. Dyn. 31(1): 179-194

[36] Zhang Y and Iwan W D 2002 Active interaction control of tall buildings subjected to near-field ground motions. $J$. Struct. Eng. 128(1): 69-79
[37] Zhang Y and Iwan W D 2003 Statistical performance analysis of seismic-excited structures with active interaction control. Earthq. Eng. Struct. Dyn. 32(7): 1039-1054

[38] Shih M H, Sung W P and Go C G 2002 Development of accumulated semi-active hydraulic damper. Exp. Tech. 26(5): 29-32

[39] Shih M H, Lin C I, Sung W P and Go C G 2006 Numerical analysis for the energy reduction behavior of accumulated semi-active hydraulic damper. J. Dyn. Syst. Geometr. Theories 4(1): 29-45

[40] Shih M H 1996 Eine aktive Regelung zur Schwingungsreduzierung von Bauwerken unter seiemischen Beanspruchungen. PhD Dissertation, RWTH Aachen, Germany

[41] Zhang Y and Iwan W D 2002 Protecting base-isolated structures from near-field ground motion by tuned interaction damper. J. Eng. Mech. 128(3): 287-295

[42] https://en.wikipedia.org/wiki/Hamilton\%27s_principle 